\title{
(2) OPEN ACCESS \\ Exploring injury intentionality and mechanism via ICD-10-CM injury codes and self-reported injury in a large, urban emergency department
}

\author{
Michael J Clery (D) , 1,2 Philip Joseph Hudson (D) ,' Jasmine C Moore, ${ }^{2}$ \\ Laura M Mercer Kollar (D) ," Daniel TWu ${ }^{1,2}$
}

'Department of Emergency Medicine, School of Medicine, Emory University, Atlanta, Georgia, USA

${ }^{2}$ Grady Health System, Atlanta, Georgia, USA

${ }^{3}$ Injury Prevention Program, Georgia Department of Public Health, Atlanta, Georgia, USA ${ }^{4}$ Division of Violence Prevention, National Center for Injury Prevention and Control, Centers for Disease Control and Prevention, Atlanta, Georgia, USA

\section{Correspondence to}

Dr Michael J Clery, Department of Emergency Medicine, Emory University School of Medicine, Atlanta 30322, Georgia, USA; michael.j.clery@emory.edu

Received 21 January 2020 Revised 28 July 2020 Accepted 1 August 2020
Check for updates

(C) Author(s) (or their employer(s)) 2021. Re-use permitted under CC BY-NC. No commercial re-use. See rights and permissions. Published by BMJ.

To cite: Clery MJ, Hudson PJ, Moore JC, et al. Inj Prev 2021:27:i62-i65.

\section{ABSTRACT}

Health systems capture injuries using International Statistical Classification of Diseases and Related Health Problems, 10th Revision, Clinical Modification (ICD-10CM) diagnostic codes and share data with public health to inform injury surveillance. This study analyses providerassigned ICD-10-CM injury codes among self-reported injuries to determine the effectiveness of ICD-10-CM coding in capturing injury and assault.

Methods Self-reported injury screen records from an urban, level 1 trauma centre collected between 20 November 2015 and 30 September 2019 were compared with corresponding provider-assigned ICD-10-CM codes discerning the frequency in which intentions are indicated among patients reporting (1) any injury and (2) assault. Results Of 380922 patients screened, 32788 (8.61\%) reported any injury and $6763(1.78 \%)$ reported assault. ICD10-CM codes had a sensitivity of $67.40 \%(95 \% \mathrm{Cl} 66.89 \%$ to $67.91 \%)$ for any injury and specificity of $89.79 \%$ (95\% Cl 89.69\% to $89.89 \%$ ]). For assault, ICD-10-CM codes had sensitivity of $2.25 \%(95 \% \mathrm{Cl} 1.91 \%$ to $2.63 \%)$ and specificity of $99.97 \%$ ( $95 \% \mathrm{Cl}$ 99.97\% 99.98\%).

Discussion This study found provider-assigned ICD-10-CM had limited sensitivity to identify injury and low sensitivity for assault. This study more fully characterises ICD-10-CM coding system effectiveness in identifying assaults.

\section{INTRODUCTION}

Violent injury is a leading cause of morbidity and mortality in the USA. ${ }^{1}$ Among African American adolescents, homicide is the leading cause of death ${ }^{1}$ ; and for every homicide there are 94 non-fatal violent injuries. ${ }^{2}$ A majority of the violent injuries treated in the emergency department (ED) are not reported to law enforcement. ${ }^{34}$

Injury surveillance describes the relative magnitude of injury type, monitors trends in injuries, identifies new injury burdens and evaluates prevention and intervention efforts; injury surveillance data are subsequently used to inform research and intervention. ${ }^{5}$ Healthcare providers are required to use the International Statistical Classification of Diseases and Related Health Problems, 10th Revision, Clinical Modification (ICD-10-CM) to report medical data to the US Department of Health and Human Services. ${ }^{6}$

A recent study evaluating the impact of the transition from ICD-9-CM to ICD-10-CM confirmed the increased specificity of ICD-10-CM by decreasing the use of codes with undetermined intent and increased identification of assaults based on injury codes. $^{7}$ The degree to which these ICD-10-CM external cause codes are reliably used in clinical practice to identify intentional injury is unclear.

This study provides insight into a population identified through a violence prevention effort that specifically and prospectively identifies victims of assault or interpersonal violence, rather than relying on external cause codes to identify mechanism and intent. While one may infer a stab wound or gunshot wound results from violence, a diagnosis of 'head injury' could result from a motor vehicle crash, a sports injury or a physical assault. This study analyses ICD-10-CM injury codes in patients with a self-reported injury screener to determine the effectiveness of provider-assigned ICD-10-CM coding in capturing injury intentionality.

\section{METHODS}

Patients presenting to the ED of a large, Southeastern US urban hospital were screened for intentional injuries. The ED is located at a designated level I trauma centre with an annual census of over 150000 patient visits per year. Approximately $70 \%-86 \%$ of ED patients were screened by a nurse verbally asking the patient questions relating to injury and interpersonal violence as part of the Cardiff Violence Prevention Model, a violence prevention programme. ${ }^{8}$ Answers were recorded in the electronic medical record.

The dataset consisted of 380922 ED records for adult patients who were screened at triage between 20 November 2015 and 30 September 2019. Data included demographics (age, race and sex), responses to the injury screener and provider-assigned ICD-10-CM codes. $^{8}$ Providers, including residents, nurse practitioners, physician assistants and attending physicians, assigned final diagnosis ICD-10-CM code(s) for each patient at the end of the patient's encounter.

The injury screen contains two questions analysed here: 'were you injured?' and 'was someone trying to hurt you?' Records were identified as containing a self-reported injury if 'yes' was answered for the first question and as assault or interpersonal violence cases if they answered 'yes' to both. To identify cases coded for injury and assault using ICD-10-CM diagnostic codes, every ICD-10-CM code assigned to each record was scanned for any relevant injury diagnosis codes (table 1). Records were identified as an assault if they contained any assault codes from the ICD-10-CM. ${ }^{9}$ Using self-reported injury and assault as reference standards, sensitivity and specificity were calculated for ICD-10-CM codes capturing injury and assault 
Table 1 ICD-10-CM codes used to identify emergency department records coded for injury and assault

\begin{tabular}{|c|c|}
\hline ICD-10-CM codes & Definitions \\
\hline \multicolumn{2}{|l|}{ Injury* } \\
\hline All S codes & Anatomic injuries \\
\hline T07-T34 & Foreign bodies, burns, corrosions, frostbite \\
\hline T66-T76 & $\begin{array}{l}\text { Other and unspecified effects of external causes (radiation, } \\
\text { heat, light, hypothermia, hyperthermia, asphyxiation, child } \\
\text { and adult abuse, lightning, drowning, motion sickness, etc) }\end{array}$ \\
\hline T79 & $\begin{array}{l}\text { Certain early complications of trauma, not elsewhere } \\
\text { classified }\end{array}$ \\
\hline 09A.2-09A.5 & $\begin{array}{l}\text { Injury, poisoning and certain other consequences of external } \\
\text { causes; and physical, sexual and psychological abuse } \\
\text { complicating pregnancy, childbirth and the puerperium }\end{array}$ \\
\hline T84.04 & Periprosthetic fracture around internal prosthetic joint \\
\hline M97 & Periprosthetic fracture around internal prosthetic joint \\
\hline \multicolumn{2}{|l|}{ Assault } \\
\hline X92-Y09 & $\begin{array}{l}\text { Intentional injury inflicted by another person, by any } \\
\text { mechanism. }\end{array}$ \\
\hline
\end{tabular}

*Source: Injury codes and definitions from Hedegaard and Johnson (2019), Table C, excluding codes T36-T65 related to drug overdose and non-drug poisoning. ICD-10-CM, International Statistical Classification of Diseases and Related Health Problems, 10th Revision, Clinical Modification.

respectively in the provider-coded electronic health records. Data analysis was conducted using SAS V.9.4.

Neither patients or the public were involved in the design, conduct, reporting or dissemination plans of our research.

\section{RESULT}

In the 380922 records examined, 32788 (8.61\%) patients selfreported any injury and a subset of 6763 (1.78\%) reported assault. Additionally, by ICD-10-CM code identification, 57656 (15.14\%) injury cases and $258(0.07 \%)$ assault cases were identified. Patients were predominantly non-Hispanic black $(76.9 \%$; $\mathrm{n}=292875)$ and male $(57 \% ; \mathrm{n}=217905)$; see table 2 .

Table 3 contains the sensitivity, specificity and predictive values of both injury and assault in ICD-10-CM codes. For any injury, ICD-10-CM codes had a sensitivity of $67.40 \%$ (95\% CI $66.89 \%$ to $67.91 \%)$ and specificity of $89.79 \%$ (95\% CI $89.69 \%$ to $89.89 \%$ ). Positive predictive value was $38.3 \%$ (95\% CI $37.93 \%$
Table 2 Characteristics of the study population

\begin{tabular}{|lc}
\hline Characteristics & $\begin{array}{c}\text { All records reviewed } \\
(\mathbf{n}=380922)\end{array}$ \\
\hline Age & $47.62(16.24)$ \\
\hline Mean (SD) & $320(0.08)$ \\
\hline Missing/unknown, $n(\%)$ & $35760(9.39)$ \\
\hline Race/ethnicity, $\mathrm{n}(\%)$ & $292875(76.89)$ \\
\hline White, non-Hispanic & $34812(9.14)$ \\
\hline Black, non-Hispanic & $2227(0.58)$ \\
\hline Hispanic & $155(0.04)$ \\
\hline Asian & $711(0.19)$ \\
\hline NHOPI & $1155(0.30)$ \\
\hline AlAN & $2083(0.55)$ \\
\hline Multiracial & $11144(2.93)$ \\
\hline Other & \\
\hline Missing or unknown & $217905(57.20)$ \\
\hline Gender, $n$ (\%) & $162778(42.73)$ \\
\hline Male & $239(0.06)$ \\
\hline Female
\end{tabular}

AIAN, American Indian/Alaska Native; NHOPI, Native Hawaiian or Other Pacific Islander.

to $38.73 \%)$ and negative predictive value was $96.69 \%(95 \% \mathrm{CI}$ $96.63 \%$ to $96.75 \%)$. For assault, ICD-10-CM codes had a sensitivity of $2.25 \%$ (95\% CI $1.91 \%$ to $2.63 \%])$ and specificity of $99.97 \%$ (95\% CI 99.97\% to $99.98 \%]$ ). Positive predictive value was $58.91 \%$ (95\% CI $52.64 \%$ to $64.98 \%)$ and negative predictive value was $98.26 \%$ (95\% CI $98.22 \%$ to $98.3 \%$ ).

Both self-report (screener) and ICD-10-CM codes identified injury and violence, and 22099 records were identified by both methods, 35557 were identified via ICD-10-CM code alone and 10689 were identified by injury screener alone. There were distinct instances where an injury was only found via one method. The top 10 primary diagnosis codes were reviewed (table 4). The top primary diagnoses in cases identified only by ICD-10-CM code were S-codes (eg, injury) with many related to injuries to the head (eg, open wound of head, superficial injury of head), whereas the top diagnoses for cases identified via the

\begin{tabular}{|c|c|c|c|c|}
\hline & $\begin{array}{l}\text { Injury screener } \\
\text { Cases }(n)\end{array}$ & $\begin{array}{l}\text { Injury screener } \\
\text { Non-cases (n) }\end{array}$ & Total & Results \\
\hline \multicolumn{5}{|l|}{ Injury } \\
\hline $\begin{array}{l}\text { ICD-10-CM } \\
\text { Cases (n) }\end{array}$ & 22099 & 35557 & 57656 & $\begin{array}{l}\text { Positive predictive value (\%) } \\
38.33(95 \% \mathrm{Cl} 37.93 \text { to } 38.73)\end{array}$ \\
\hline $\begin{array}{l}\text { ICD-10-CM } \\
\text { Non-cases (n) }\end{array}$ & 10689 & 312577 & 323266 & $\begin{array}{l}\text { Negative predictive value (\%) } \\
96.69(95 \% \mathrm{Cl} 96.63 \text { to } 96.75)\end{array}$ \\
\hline Total & 32788 & 348134 & 380922 & \\
\hline Results & $\begin{array}{l}\text { Sensitivity (\%) } \\
67.40 \text { (95\% Cl } 66.89 \text { to } 67.91)\end{array}$ & $\begin{array}{l}\text { Specificity (\%) } \\
89.79 \text { (95\% Cl } 89.69 \text { to } 89.89)\end{array}$ & & \\
\hline \multicolumn{5}{|l|}{ Assault } \\
\hline $\begin{array}{l}\text { ICD-10-CM } \\
\text { Cases (n) }\end{array}$ & 152 & 106 & 258 & $\begin{array}{l}\text { Positive predictive value (\%) } \\
58.91 \text { (95\% Cl } 52.64 \text { to } 64.98)\end{array}$ \\
\hline $\begin{array}{l}\text { ICD-10-CM } \\
\text { Non-cases (n) }\end{array}$ & 6611 & 374053 & 380664 & $\begin{array}{l}\text { Negative predictive value (\%) } \\
98.26(95 \% \mathrm{Cl} 98.22 \text { to } 98.30)\end{array}$ \\
\hline Total & 6763 & 374159 & 380922 & \\
\hline Results & $\begin{array}{l}\text { Sensitivity (\%) } \\
2.25(95 \% \mathrm{Cl} 1.91 \text { to } 2.63)\end{array}$ & $\begin{array}{l}\text { Specificity (\%) } \\
99.97 \text { ( } 95 \% \text { Cl } 99.97 \text { to 99.98) }\end{array}$ & & \\
\hline
\end{tabular}

ICD-10-CM, International Statistical Classification of Diseases and Related Health Problems, 10th Revision, Clinical Modification. 
Table 4 Leading primary diagnosis codes among injury cases captured by only one tool

\begin{tabular}{|c|c|c|c|c|c|}
\hline \multicolumn{3}{|c|}{ ICD-10-CM only $(n=35557)$} & \multicolumn{3}{|c|}{ Injury screener only ( $n=10689$ ) } \\
\hline Primary DX & Definition & $\mathrm{n}(\%)$ & Primary DX & Definition & $\mathrm{n}(\%)$ \\
\hline S01 & Open wound of head & $2028(5.7)$ & M25 & $\begin{array}{l}\text { Other joint disorder, not } \\
\text { elsewhere classified }\end{array}$ & $2125(19.88)$ \\
\hline SO0 & Superficial injury of head & $1308(3.68)$ & M54 & Dorsalgia & $1984(18.56)$ \\
\hline S61 & Open wound of wrist, hand and fingers & $1214(3.41)$ & M79 & $\begin{array}{l}\text { Other and unspecified soft } \\
\text { tissue disorders, not elsewhere } \\
\text { classified }\end{array}$ & $1060(9.92)$ \\
\hline S16 & $\begin{array}{l}\text { Injury of muscle, fascia and tendon at neck } \\
\text { level }\end{array}$ & $1204(3.39)$ & R07 & Pain in throat and chest & $548(5.13)$ \\
\hline S82 & Fracture of patella & $1202(3.38)$ & R51 & Headache & $445(4.16)$ \\
\hline S39 & $\begin{array}{l}\text { Other and unspecified injuries of abdomen, } \\
\text { lower back, pelvis and external genitals }\end{array}$ & $1143(3.21)$ & Z04 & $\begin{array}{l}\text { Encounter for examination or } \\
\text { observation for other reasons }\end{array}$ & $240(2.25)$ \\
\hline $\mathrm{SO2}$ & Fracture of skull and facial bones & $928(2.61)$ & R10 & Abdominal and pelvic pain & $238(2.23)$ \\
\hline S06 & Concussion & $911(2.56)$ & F10 & Alcohol-related disorders & $221(2.07)$ \\
\hline S62 & Fracture of navicular bone of wrist & $807(2.27)$ & R55 & Syncope and collapse & $191(1.79)$ \\
\hline S09 & Other and unspecified injuries of head & $772(2.17)$ & G40 & Epilepsy and recurrent seizures & $113(1.06)$ \\
\hline
\end{tabular}

ICD-10-CM, International Statistical Classification of Diseases and Related Health Problems, 10th Revision, Clinical Modification.

injury screener alone contained a variety of codes from other ICD-10-CM chapters largely related to pain in a region of the body instead of an injury.

\section{DISCUSSION}

Provider-assigned ICD-10-CM codes did not reliably identify injuries and assaults that were self-reported in an ED screen. Although specificity was high for ICD-10-CM codes to identify injury, the sensitivity was less than $70 \%$ despite injury codes identifying almost twice the number of encounters for injury as those actually self-reported (15.14\% and $8.61 \%$, respectively). Based on this analysis, both ICD-10-CM codes and self-report have overlap and complement each other with additional identification of injury. For surveillance purposes, this is a concern because certain types of injuries are then likely to be systematically overlooked and trends that may reflect risks to public health may not be detectable if relying exclusively on one method.

Assault was poorly identified by provider-assigned ICD-10-CM external cause codes, which had only a $2.25 \%$ sensitivity for self-reported assault injury. This demonstrates a severe barrier to identification and monitoring of the violent injury burden and raises concern for underestimation of incidence and prevalence. Intentionality components of injury codes may be even more frequently included in this analysis than in typical practice of injury surveillance by public health entities as it included not only the primary diagnosis code, but all ICD-10-CM codes associated with the encounter. Future research may consider examining the differences in sensitivity when performed by professional coders as compared with provider coded records.

This study has several limitations as this was performed at a single, urban, level 1 trauma-designated centre and may not reflect the broader injury and assault trends across the nation. Also, providers assigned diagnostic codes rather than using medical coding services. We expect this may limit the number of diagnoses applied given only one code is required to complete the patient encounter and additional time is required to record qualifiers associated with a diagnosis. The implications would be better understood with broader study of how ICD-10-CM codes are assigned beyond this single centre. Nurses are trained to request violent injury information and patients only reveal information they feel comfortable sharing. Increased nurse refresher training on the screen may be needed to improve mechanism reporting. More exploration of patient perceptions of the screen and hesitancy to report intentionality or mechanism could be a focus of future research.

Despite these limitations, these data show high specificity and negative predictive values for injury and assault. More work is needed to understand what factors most affect sensitivity such as who assigns codes (provider or medical coding service), coding practices and training for ICD-10-CM. If high specificity can be maintained and sensitivity significantly increased, ICD-10-CM codes may provide important surveillance information for injury and assault patterns.

\section{CONCLUSION}

In this study, provider-assigned ICD-10-CM codes and selfreported injury both demonstrated gaps in surveillance. Improvements are needed in implementation of ICD-10-CM use, especially to improve their reliability for assault injuries. Injury surveillance methods should seek to improve ICD-10-CM use and explore additional measures for the identification and trending of violence and injuries for population health.

\section{What is already known on the subject}

- International Statistical Classification of Diseases and Related Health Problems, 10th Revision, Clinical Modification health system data are reported to the US Department of Health and Humans Services.

- Data are used for injury and violence surveillance.

Acknowledgements The authors thank all the dedicated providers who are tasked with assigning ICD-10-CM codes and the authors especially thank the nursing staff who are integral to preventing violence using the Cardiff Model Screening Tool.

Contributors MJC, PJH, JCM, LMMK and DTW contributed to the design and implementation of the study. PJH performed the analysis. All authors discussed the results and contributed to the writing of the manuscript.

Funding The authors have not declared a specific grant for this research from any funding agency in the public, commercial or not-for-profit sectors.

Disclaimer The findings and conclusions in this report are those of the authors anddo not necessarily represent the official position of the Centers for Disease Control and Prevention. 


\section{What this study adds}

- Characterises the effectiveness of provider-assigned International Statistical Classification of Diseases and Related Health Problems, 10th Revision, Clinical Modification (ICD$10-\mathrm{CM}$ ) codes in capturing injury and interpersonal violence experiences relative to self-reported injury and interpersonal violence.

- Provides preliminary evidence that more complete use of ICD-10-CM codes is needed to accurately reflect injury and interpersonal violence experiences.

\section{Competing interests None declared.}

Patient and public involvement Patients and/or the public were not involved in the design, or conduct, or reporting, or dissemination plans of this research.

Patient consent for publication Not required.

Ethics approval This study was determined exempt by the Emory Institutional Review Board (IRB00115147).

Provenance and peer review Commissioned; externally peer reviewed.

Open access This is an open access article distributed in accordance with the Creative Commons Attribution Non Commercial (CC BY-NC 4.0) license, which permits others to distribute, remix, adapt, build upon this work non-commercially, and license their derivative works on different terms, provided the original work is properly cited, appropriate credit is given, any changes made indicated, and the use is non-commercial. See: http://creativecommons.org/licenses/by-nc/4.0/.

\section{ORCID iDs}

Michael J Clery http://orcid.org/0000-0002-1701-1289

Philip Joseph Hudson http://orcid.org/0000-0002-2958-8181

Laura M Mercer Kollar http://orcid.org/0000-0001-9517-7690

\section{REFERENCES}

1 Centers for Disease Control and Prevention. Web-Based injury statistics query and reporting system (WISQARS) 2018.

2 Centers for Disease Control and Prevention. Nonfatal physical assault-related injuries treated in hospital emergency departments - United States. MMWR Morb Mortal Wkly Rep 2000.

3 Wu DT, Moore JC, Bowen DA, et al. Proportion of violent injuries unreported to law enforcement. JAMA Intern Med 2019;179:111-112.

4 Bureau of Justice Statistics. Criminal Victimization,2016:Revised 2018.

5 Institute of Medicine. Reducing the burden of injury: advancing prevention and treatment. Washington DC: The National Academies Press, 1999.

6 Department of Health and Human Services. HIPAA administrative simplification: modifications to medical data code set standards to adopt ID-10-CM and ICD-10-PCS. final rule, 2009. Available: https://www.govinfo.gov/content/pkg/FR-2009-01-16/pdf/E9-743.pdf

7 Slavova S, Costich JF, Luu H, et al. Interrupted time series design to evaluate the effect of the ICD-9-CM to ICD-10-CM coding transition on injury hospitalization trends. Inj Epidemiol 2018;5:36.

8 Mercer Kollar LM, Sumner SA, Bartholow B, et al. Building capacity for injury prevention: a process evaluation of a replication of the Cardiff violence prevention programme in the southeastern USA. Inj Prev 2020;26:221-8.

9 National Center for Health Statistics. International classification of diseases, tenth revision, clinical modification (ICD-10-CM), 2019. Available: https://www.cdc.gov/ nchs/icd/icd $10 \mathrm{~cm}$. htm 